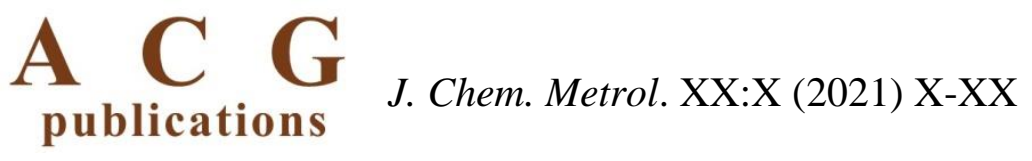

\title{
Development of a quick reverse phase liquid chromatographic method with photodiode-array detection for quantitative determination of chlorthalidone, metoprolol succinate and telmisartan in tablet formulation
}

\author{
Avani Chokshi ${ }^{1 *}{ }^{*}$, Rohit Prajapati ${ }^{1}$, Pritesh Desai ${ }^{\circ}{ }^{2}$ and \\ Mehul Patel
}

Ramanbhai Patel College of Pharmacy, Charotar University of Science and Technology, CHARUSAT

Campus, Changa - 388421, Anand, Gujarat, India

Department of Analytical Research, PTC-Moraiya, Zydus Cadila Healthcare Limited, NH 8A, Moraiya382213, Gujarat, India

(Received June 12, 2021; Revised August 13, 2021; Accepted August 17, 2021)

\begin{abstract}
A quick and simple reversed-phase High-Performance Liquid Chromatographic method (RP-HPLC) with isocratic elution has been developed and validated for the concurrent quantitative determination of chlorthalidone, metoprolol succinate and telmisartan in the bulk mixture and tablet dosage form. The chromatographic separation was performed using Inertsil Octadecyl-Silica (ODS- $\left.\mathrm{C}_{18}\right)$ Column $(150 \mathrm{~mm} \times 4.6 \mathrm{~mm}, 5 \mu \mathrm{m})$ stationary phase. The separation and elution was carried out using a mobile phase mixture of phosphate buffer $(50 \mathrm{mM}, \mathrm{pH} 2.5)$ and acetonitrile at a ratio of $40: 60 \mathrm{v} / \mathrm{v}$ and $0.7 \mathrm{~mL} / \mathrm{min}$ flow rate. Chlorthalidone, metoprolol succinate and telmisartan were eluted at $2.96 \pm 0.5 \mathrm{~min}, 4.31 \pm 0.5 \mathrm{~min}$ and $5.94 \pm 0.5 \mathrm{~min}$ respectively. The response was recorded using a photodiode array (PDA) detector at $225 \mathrm{~nm}$ wavelength. The selected method was linear in the range of 3.21-18.72 $\mu \mathrm{g} / \mathrm{mL}, 6.25-37.50 \mu \mathrm{g} / \mathrm{mL}$ and $10-60 \mu \mathrm{g} / \mathrm{mL}$ while percentage recovery was in the range from 99.15 to $99.93 \%$, 99.15 to $99.42 \%$ and 100.03 to $100.08 \%$ for chlorthalidone, metoprolol succinate and telmisartan respectively. The method was found to be sensitive, selective, linear and reproducible and the results obtained suggest the suitability of the developed method for routine analysis of the formulations containing the combination of these drugs.
\end{abstract}

Keywords: Chlorthalidone; high-performance liquid chromatography; metoprolol succinate; telmisartan; validation. () 2021 ACG Publications. All rights reserved.

\footnotetext{
* Corresponding author E-Mail: avanichokshi.ph@charusat.ac.in

The article was published by ACG Publications http://www.acgpubs.org/journal/journal-of-chemical-metrology Month-Month 2021 EISSN:1307-6183 DOI:http://doi.org/10.25135/jcm.6012106.2098 Available online: August 24, 2021
} 
Determination of chlorthalidone, metoprolol succinate and telmisartan in tablet formulation

\section{Introduction}

One of the primary worldwide reasons for cardiovascular disorders and early death is hypertension [1,2]. Even though, over the past few decades, the global average blood pressure has reduced slightly because of the extensive use of antihypertensive medications, the prevalence of hypertension has increased. The worldwide increased number of hypertensive population is majorly due to the aging of the population and an unhealthy lifestyle including food habits and lack of exercise [3, 4]. The adults with blood pressure deviation from $130 / 80 \mathrm{mmHg}$ value are much prone to the development of clinical cardiovascular disorders such as coronary heart disease, heart failure and stroke. The treatment options for adult hypertensive patients include lifestyle measures together with suitable drug therapy $[5,6]$. While the majority of the patients with hypertension rely on drug therapy, the clinical studies suggest the inefficiency of the single drug for the control of hypertension in the patients, especially those with comorbid conditions. Therefore, combination drug therapy including two or more drugs is the typical requirement [7]. Chlorthalidone belongs to the class of thiazide diuretics which removes extra water and few electrolytes from the body through urine. This reduces the total blood volume and blood pressure and later on, it relaxes blood vessels to improve the blood flow [8]. Metoprolol is the beta-adrenergic blocking agent which specifically acts on the cardiac adrenergic receptors and slows down the heart rate [9]. Telmisartan acts as an angiotensin II receptor blocker which inhibits angiotensin II attachment to the AT1 receptor in vascular smooth muscles and adrenal gland. This results in the reversal of vaso-constricting and aldosterone secreting effects of angiotensin II [10]. Fixed dose combination (FDC) of these three drugs is approved for reducing the uncontrolled blood pressure in the patients who do not respond to the FDC of any two drugs.

Analytical methods are aimed to identify the purity, composition and potency of the pharmaceutical formulation. Validation of the developed analytical method establishes the performance limits of the measurements of a particular method. In simple terms, the analytical methods confirms the labeled claim for the pharmaceutical formulation as it is required to deliver the prescribed amount of the drug(s) to the patients. Number of spectrophotometric [11-13] as well as normal or reverse phase chromatographic methods [14-28] are published for the quantitative determination of chlorthalidone, metoprolol succinate and telmisartan in the bulk mixture as well as pharmaceutical formulations. All those methods are either for the determination of the drug individually; in dual combination or in combination with other cardiovascular agents. Because of the availability of the approved triple combination of chlorthalidone, metoprolol succinate and telmisartan in the market and the unavailability of the approved pharmacopoeal method or any other literature reported for their simultaneous estimation, the authors had aimed to develop a simple and quick reverse-phase chromatographic method with PDA detection for the quantitative determination of chlorthalidone, metoprolol succinate and telmisartan in tablet formulation. The developed method was validated in accordance with the guidance provided by the International Council for Harmonisation of Technical Requirements for Pharmaceuticals for Human Use (ICH) Q2 (R1) [29].

\section{Experimental}

\subsection{Chemicals and Reagents}

HPLC grade solvents, reagents and chemicals were purchased from Merck India. High purity deionized water (Milli-Q) was acquired from, Millipore (Prefil Kit Integral System, Merck) water purification system. The gratis samples of chlorthalidone, metoprolol succinate and telmisartan were provided by Sun Pharmaceutical Industries Ltd. while the tablet formulation (Tablet-Met XL 3D 50 with a composition of chlorthalidone $-12.5 \mathrm{mg}$, metoprolol succinate $-25 \mathrm{mg}$ and telmisartan $-40 \mathrm{mg}$ ) was purchased from the local market.

\subsection{Chromatographic Conditions and Equipment}

The chromatographic separation and quantitative analysis of chlorthalidone, metoprolol succinate and telmisartan were performed on Shimadzu LC-2010CHT system (Shimadzu Corporation, Japan). The system was consisting of a quaternary solvent pump, an auto-sampler and a PDA detector (SPD-M20A). The chromatographic signals were observed and processed with LC solution (V 1.25) software. Based on 
the solubility and chemical nature of the analytes, the chromatographic conditions including solvent for extraction from the formulation, stationary phase for the separation and mobile phase for elution of the analytes and detection wavelength were selected. Methanol was selected as a solvent for preparation of standard and test solutions as the analytes are freely soluble in it and the solution are found to be stable. Separation of the analytes was carried out on Intersil $C_{18}$ ODS $(150 \mathrm{~mm} \times 4.6 \mathrm{~mm}, 5 \mu \mathrm{m})$ column (GL Sciences). The isocratic mobile phase system was a mixture of phosphate buffer $(50 \mathrm{mM}, \mathrm{pH} 2.5)$ and acetonitrile (40:60, v/v). Phosphate buffer was prepared by dissolving $6.8 \mathrm{~g}$ potassium dihydrogen orthophosphate in $1000 \mathrm{~mL}$ milli-Q water and $\mathrm{pH}$ was adjusted to 2.5 using orthophosphoric acid. The flow rate of the mobile phase was adjusted to $0.7 \mathrm{~mL} 7 \mathrm{~min}$, the column oven was maintained at $25^{\circ} \mathrm{C}$ and eluents were detected at $225 \mathrm{~nm}$ wavelength. The sample and standard solutions were prepared in methanol while final dilutions were made in the mobile phase. The injection volume was fixed to $10 \mu \mathrm{L}$.

\subsection{Solution Preparation}

The standard stock solutions of chlorthalidone, metoprolol succinate and telmisartan were prepared by dissolving $12.5 \mathrm{mg}, 25 \mathrm{mg}$ and $40 \mathrm{mg}$ of the drug respectively in methanol in $100 \mathrm{~mL}$ volumetric flask. $2.5 \mathrm{~mL}$ of each solutions were diluted with mobile phase in $25 \mathrm{~mL}$ volumetric flask to obtain $12.5 \mu \mathrm{g} / \mathrm{mL}, 25 \mu \mathrm{g} / \mathrm{mL}$ and $40 \mu \mathrm{g} / \mathrm{mL}$ chlorthalidone, metoprolol succinate and telmisartan respectively. The serial dilutions were made at six level concentration range to have $3.21-18.72 \mu \mathrm{g} / \mathrm{mL}$ chlorthalidone, $6.25-37.50 \mu \mathrm{g} / \mathrm{mL}$ metoprolol succinate and $10-60 \mu \mathrm{g} / \mathrm{mL}$ telmisartan. Each solution was filtered prior to injection to the chromatographic system.

For the preparation of the test solution, the finely crushed and weighed powder of 20 tablets, equivalent to $12.5 \mathrm{mg}$ chlorthalidone, $25 \mathrm{mg}$ metoprolol succinate and $40 \mathrm{mg}$ telmisartan was mixed with methanol in $100 \mathrm{~mL}$ volumetric flask, sonicated for 20 minutes and filtered through Millipore polyvinylidene fluoride (PVDF) $0.45 \mu \mathrm{m}$ syringe filter where first $3 \mathrm{~mL}$ of solution was discarded. From this, $2.5 \mathrm{~mL}$ of the solution was transferred and diluted with mobile phase in the $25 \mathrm{~mL}$ volumetric flask.

The placebo or blank solution was a mobile phase (a mixture of phosphate buffer $(50 \mathrm{mM}, \mathrm{pH}$ 2.5 ) and acetonitrile in the ratio 40:60 v/v) without addition of drug substances.

\subsection{Method Validation}

To ensure the suitability of the analytical method for its anticipated purpose, the validation of the developed method was performed as per the guidelines provided by International Council for Harmonisation (ICH) [29]. The validation was performed for the parameters including specificity, detection limit, quantification limit, linearity, range, accuracy, precision, and robustness. Linearity of the method was established in triplicate using the mixed standard solutions at six different concentration ranges. The selected range for the linearity was $3.21-18.72 \mu \mathrm{g} / \mathrm{mL}, 6.25-37.50 \mu \mathrm{g} / \mathrm{mL}$ and $10-60 \mu \mathrm{g} / \mathrm{mL}$ for chlorthalidone, metoprolol succinate and telmisartan respectively. The linear regression equation was obtained by plotting mean peak area vs. concentration. The limit of detection (LOD) and limit of quantitation (LOQ) were calculated from the standard deviation of the response and the slope using equations provided by ICH guidelines ( $\mathrm{LOD}=3.3 \times \sigma / \mathrm{S}$ and $\mathrm{LOQ}=10 \times \sigma / \mathrm{S}$ ). The precision of the method was established on the same day (intra-day) and different days (inter-day) for three independent sample solutions at three levels. The inter-day precision was performed on different days by different analysts and on different columns as per the guideline. The relative standard deviation was calculated for both inter-day and intra-day precision. The accuracy of the analytical method was identified by spiking pre-analyzed sample with the known concentration of standard solution at three concentration levels viz. 80, 100 and $120 \%$ in triplicates. Relative standard deviation (RSD\%) for the recovered sample was calculated. The robustness of the developed method was identified by including the small but careful changes in the chromatographic conditions- flow rate $( \pm 0.1 \mathrm{~mL} / \mathrm{min})$, mobile phase ratio $(39: 61 \mathrm{v} / \mathrm{v}$ and $41: 59 \mathrm{v} / \mathrm{v})$ and detection wavelength $( \pm 2 \mathrm{~nm})$ - and RSD\% was calculated. 
Determination of chlorthalidone, metoprolol succinate and telmisartan in tablet formulation

\section{Results and discussion}

\subsection{Method Development}

The main target for the development of the analytical method is to separate all the analytes present in the bulk mixture as well as a formulation with good resolution. The successful separation with the satisfactory peak parameters was achieved using an isocratic mobile phase system, containing phosphate buffer $(50 \mathrm{mM}, \mathrm{pH} 2.5)$ and acetonitrile $(40: 60, \mathrm{v} / \mathrm{v})$ in the Intersil $\mathrm{C}_{18}$ ODS $(150 \mathrm{~mm} \times 4.6 \mathrm{~mm}, 5 \mu \mathrm{m})$ column as a stationary phase at a flow rate of $0.7 \mathrm{~mL} / \mathrm{min}$. Based on the physicochemical properties and the chemical structure, the chromatographic conditions were selected and optimized. To prove the suitability and reproducibility of the chromatographic system, system suitability was performed by injecting six replicated injections of the solution mixture of chlorthalidone, metoprolol succinate and telmisartan at $12.5 \mu \mathrm{g} / \mathrm{mL}, 25 \mu \mathrm{g} / \mathrm{mL}$ and $40 \mu \mathrm{g} / \mathrm{mL}$ concentration respectively.

\subsection{Method Validation}

\subsubsection{System Suitability}

System suitability was checked for the six replicates of chlorthalidone, metoprolol succinate and telmisartan at $12.5 \mu \mathrm{g} / \mathrm{mL}, 25 \mu \mathrm{g} / \mathrm{mL}$ and $40 \mu \mathrm{g} / \mathrm{mL}$ concentration respectively (Figure 1). The results of the study confirm the suitability and reproducibility of the chromatographic system for the current analytical work. The results for the peak properties with the acceptable limits specified by the ICH guidelines are shown in Table $1[29,30]$.

Table 1. System suitability data (mean $\pm \mathrm{RSD} \% ; \mathrm{n}=6$ )

\begin{tabular}{cccc}
\hline Par.ameter & Chlorthalidone & Metoprolol succinate & Telmisartan \\
\hline Relative retention $(\mathrm{min})$ & $2.96 \pm 0.28$ & $4.31 \pm 0.19$ & $5.94 \pm 0.13$ \\
Theoretical Plates $(\mathrm{N}>2000)$ & $2262.41 \pm 0.68$ & $3118.32 \pm 0.82$ & $3608.58 \pm 0.68$ \\
Tailing factor $(\mathrm{T} \leq 2)$ & $1.29 \pm 1.3$ & $1.38 \pm 1.7$ & $1.29 \pm 0.8$ \\
Resolution $\left(\mathrm{R}_{\mathrm{s}}>2\right)$ & $10.37 \pm 0.28$ & $4.78 \pm 0.40$ & $3.47 \pm 0.49$ \\
Capacity factor $\left(\mathrm{k}^{\prime}>2.0\right)$ & $2.37 \pm 0.59$ & $3.47 \pm 0.48$ & $4.755 \pm 0.58$ \\
\hline PDA Ch1 $225 \mathrm{~nm} 4 \mathrm{~nm}$ & & & \\
mAU & & &
\end{tabular}

(a)

PDA Ch1 225nm 4nm $\mathrm{mAU}$

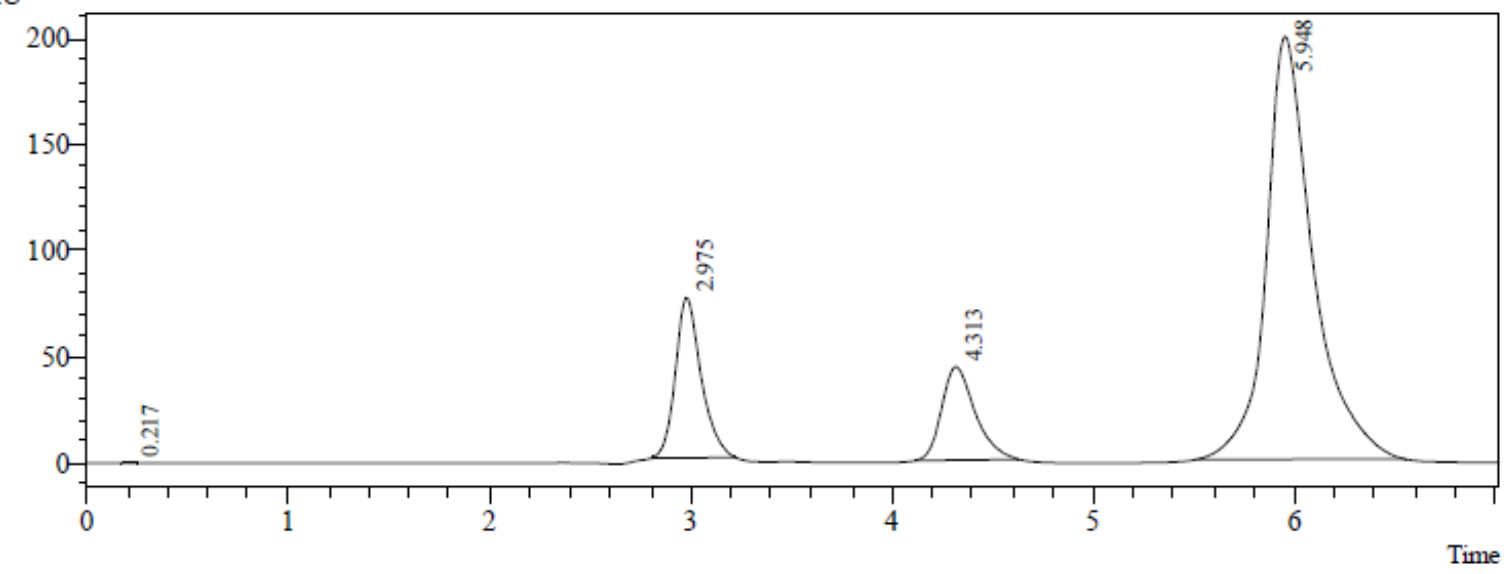

(b)

Figure 1. Chromatogram for (a) Placebo solution (mobile phase without analytes) (b) System suitability 


\subsubsection{Specificity}

The peak purity of the analytes in test, standard and spiked solutions was checked to establish the specificity of the developed method. PDA detector was employed for assessing purity and homogeneity of all the peaks for chlorthalidone, metoprolol succinate and telmisartan. For each of them, the peak purity index was found to be near to 1 using the LC solution software. The results indicate unaffected chromatographic separation of chlorthalidone, metoprolol succinate and telmisartan even in the presence of the excipients in the tablet formulation.

\subsubsection{Linearity and Range}

The linearity of the method was established to confirm that the results obtained for the selected range are in direct proportion to the concentration of analytes. The plot of peak area vs. concentration was linear at a range of $3.21-18.72 \mu \mathrm{g} / \mathrm{mL}(3.21,6.25,9.37,12.50,15.62$ and $18.72 \mu \mathrm{g} / \mathrm{mL})$ for Chlorthalidone $6.25-37.50 \mu \mathrm{g} / \mathrm{mL}(6.25,12.50,18.75,25,31.25,37.50 \mu \mathrm{g} / \mathrm{mL})$ for Metoprolol succinate and 10-60 $\mu \mathrm{g} / \mathrm{mL}(10,20,30,40,50,60 \mu \mathrm{g} / \mathrm{mL}$ ) for Telmisartan (Figure 2). The linear regression analysis data are summarized in Table 2.

Table 2. Summary of validation parameters

\begin{tabular}{cccc}
\hline $\begin{array}{c}\text { Validation } \\
\text { Parameter } \\
\text { Acceptable Limits) }\end{array}$ & Chlorthalidone & Metoprolol succinate & Telmisartan \\
\hline Peak Purity Index $(\sim 1)$ & 0.999992 & 0.999960 & 0.999997 \\
Linearity $(\mu \mathrm{g} / \mathrm{mL})$ & $3.21-18.72$ & $6.25-37.50$ & $10-60$ \\
Linearity Equation & $\mathrm{Y}=63018 \mathrm{X}+2630.4$ & $\mathrm{Y}=25306 \mathrm{X}+15776$ & $\mathrm{Y}=76869 \mathrm{X}+16710$ \\
$\mathrm{r}^{2}(\sim 1)$ & 0.9999 & 0.9998 & 0.9998 \\
LOD $(\mu \mathrm{g} / \mathrm{mL})$ & 0.59 & 1.21 & 2.12 \\
LOQ $(\mu \mathrm{g} / \mathrm{mL})$ & 1.79 & 3.66 & 6.44 \\
Repeatability $(\mathrm{RSD} \%$ & $0.41-1.30$ & $0.33-0.48$ & $0.30-0.58$ \\
$<2)$ & & & \\
Intermediate Precision & $0.65-1.61$ & $0.62-1.09$ & $0.78-0.93$ \\
$(\mathrm{RSD} \%<2)$ & & & \\
\hline
\end{tabular}

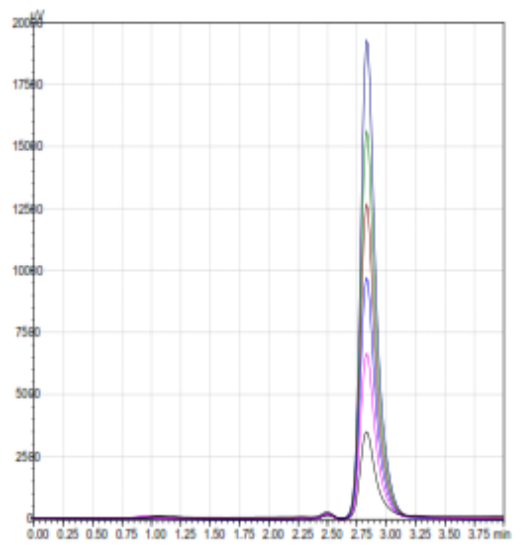

(a)

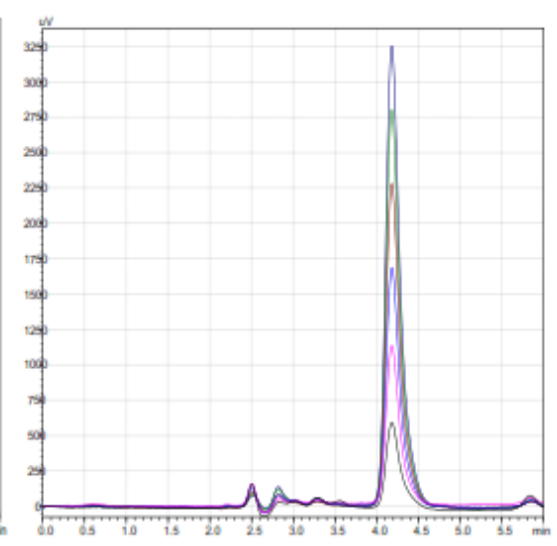

(b)

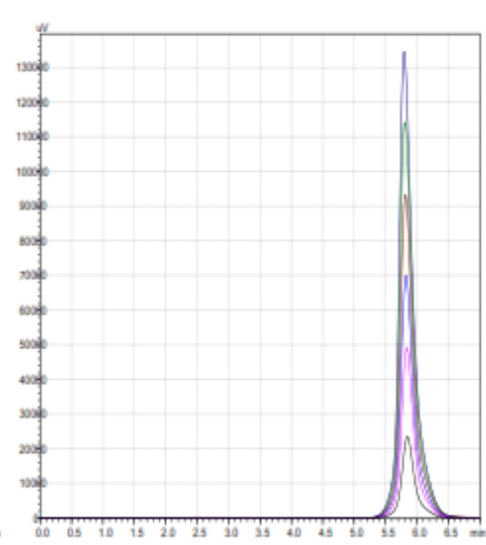

(c)

Figure 2. Overlay chromatograms for (a) Chlorthalidone, (b) Metoprolol succinate and (c) Telmisartan 


\subsection{4. $L O D$ and $L O Q$}

Sensitivity of any analytical method for detecting and quantifying the drug substances in a given sample is shown by its detection (LOD) and quantification (LOQ) limits. The LOD and LOQ for the analytes were calculated from the equation suggested in the ICH guidelines:

$\mathrm{LOD}=3.3 \times \sigma / \mathrm{S}$ and

$\mathrm{LOQ}=10 \times \sigma / \mathrm{S}$

Where " $\sigma$ is the standard deviation of the response" and "S is the slope of the calibration curve". LOD and LOQ values for chlorthalidone, metoprolol succinate and telmisartan are given in Table 2.

\subsubsection{Accuracy}

The accuracy of the developed method was assessed at three levels- $80 \%, 100 \%$ and $120 \%$ by spiking the known concentration of sample solution. \% recovery was obtained for the analytes at each level of the studies. The results of the accuracy studies indicate non-interference of the excipients during the chromatographic elution of analytes. The results for the accuracy studies for the developed method are shown in Table 3 . The higher values of the \% recovery confirms the accuracy of developed method.

Table 3. Results of accuracy $(\mathrm{n}=3)$

\begin{tabular}{cccc}
\hline \multirow{2}{*}{$\begin{array}{c}\text { Recovery } \\
\text { Level }\end{array}$} & \multicolumn{3}{c}{ \% Recovery $($ Mean \pm RSD\%; $\mathbf{n = 3})$} \\
\cline { 2 - 4 } & Chlorthalidone & $\begin{array}{c}\text { Metoprolol } \\
\text { succinate }\end{array}$ & Telmisartan \\
\hline $80 \%$ & $99.9 \pm 0.25$ & $99.2 \pm 0.14$ & $100.1 \pm 0.34$ \\
$100 \%$ & $99.2 \pm 0.21$ & $99.2 \pm 0.20$ & $99.6 \pm 0.20$ \\
$120 \%$ & $99.8 \pm 0.16$ & $99.4 \pm 0.13$ & $100.0 \pm 0.14$ \\
\hline
\end{tabular}

\subsubsection{Precision}

The precision of the developed analytical method was assessed by determining the repeatability and intermediate precision. The repeatability (intraday precision) of the method was checked at three concentration levels- low, middle and high- for each of the analytes three times on the same day. The intermediate precision was performed by the same method as repeatability but the analysis was performed on three different days, by different analysts and on different columns. The results for the precision studies are provided in Table 2 in terms of RSD\% for each analysis. The value of RSD\% lesser than 1 confirms the repeatability of the proposed method.

\subsubsection{Robustness}

The robustness of the analytical methods indicates the reliability of the developed method upon the small changes carried out either intentionally or unintentionally by the analyst. The same for the developed method was confirmed by performing the changes in the mobile phase composition, wavelength of detection and flow rate of the mobile phase. RSD\% was calculated for each of the chromatographic experiments and results (RSD\% <1) confirmed the robustness of the developed method as shown in Table 4. 
Table 4. Results of robustness $(n=3)$

\begin{tabular}{|c|c|c|c|c|c|}
\hline \multirow[b]{2}{*}{ Parameter } & \multirow[b]{2}{*}{$\begin{array}{l}\text { Normal } \\
\text { condition }\end{array}$} & \multirow[b]{2}{*}{$\begin{array}{l}\text { Change in the } \\
\text { condition }\end{array}$} & \multicolumn{3}{|c|}{ \% Recovery $($ Mean \pm RSD\% ; $n=3)$} \\
\hline & & & Chlorthalidone & $\begin{array}{c}\text { Metoprolol } \\
\text { succinate }\end{array}$ & Telmisartan \\
\hline \multirow{2}{*}{ Wavelength } & \multirow{2}{*}{$225 \mathrm{~nm}$} & $-2 \mathrm{~nm}$ & $101.3 \pm 1.13$ & $100.0 \pm 0.59$ & $100.9 \pm 1.13$ \\
\hline & & $+2 \mathrm{~nm}$ & $98.8 \pm 0.20$ & $100.0 \pm 0.54$ & $99.7 \pm 0.90$ \\
\hline \multirow{2}{*}{ Flow Rate } & \multirow{2}{*}{$0.7 \mathrm{~mL} / \mathrm{min}$} & $-5 \%$ & $99.7 \pm 0.34$ & $99.8 \pm 0.49$ & $101.6 \pm 0.46$ \\
\hline & & $+5 \%$ & $98.4 \pm 0.57$ & $99.6 \pm 0.46$ & $99.6 \pm 1.21$ \\
\hline Mobile Phase & Buffer: ACN & $-2 \%$ & $99.3 \pm 0.72$ & $100.1 \pm 1.27$ & $100.0 \pm 1.70$ \\
\hline Composition & 40:60 & $+2 \%$ & $99.4 \pm 0.59$ & $100.1 \pm 0.48$ & $100.5 \pm 1.30$ \\
\hline
\end{tabular}

\subsubsection{Application of the Method}

At the optimized chromatographic conditions, the tablet sample solution containing chlorthalidone, metoprolol succinate and telmisartan equivalent to $12.5 \mu \mathrm{g} / \mathrm{mL}, 25 \mu \mathrm{g} / \mathrm{mL}$ and $40 \mu \mathrm{g} / \mathrm{mL}$ respectively was injected into the HPLC system (Figure 3). From the peak area, the concentration for each of the analytes was calculated to determine percentage purity. The results for the assay of the tablet formulation are reported in Table 5. The results obtained for each of the analytes are comparable to the labeled claim which confirms applicability of the proposed method for marketed formulations containing chlorthalidone, metoprolol succinate and telmisartan.

Table 5. Results for assay of tablet formulation ( $n=3)$

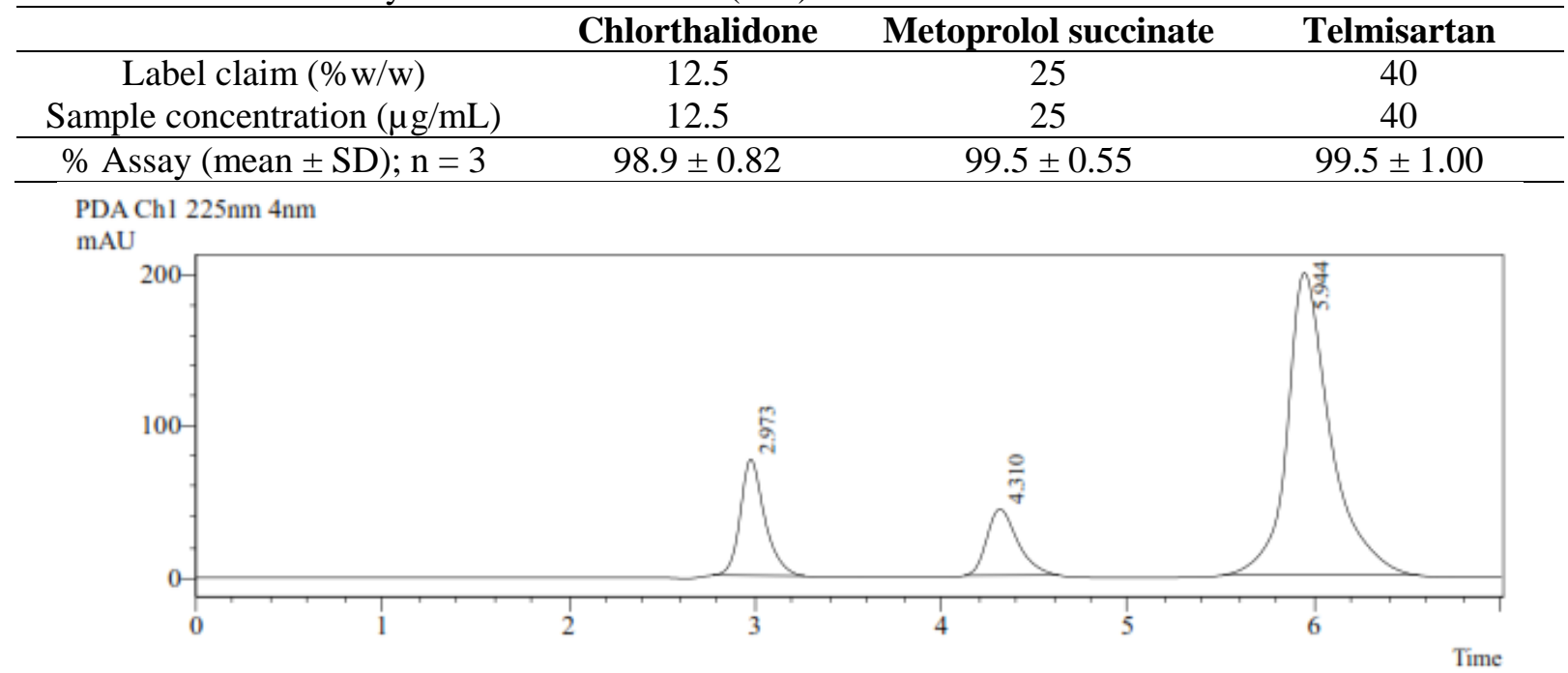

Figure 3. Assay chromatogram for the tablet formulation of Chlorthalidone, Metoprolol succinate and Telmisartan

\section{Conclusions}

A quick reverse phase liquid chromatographic method with PDA detection was developed and validated for the quantitation of chlorthalidone, metoprolol succinate and telmisartan in tablet formulation. Peaks for all analytes were well separated and every peak parameter was satisfied, indicating the suitability of the proposed method for the analytical separation and quantification of each of the analytes in the combined formulation. The developed method was validated as per the guidelines suggested in ICH and all the results are falling into the provided limits which confirms the applicability of the proposed method for the intended purpose. 


\section{Acknowledgments}

Authors for the present research work are grateful to Ramanbhai Patel College of Pharmacy, Charotar University of Science and Technology, Changa, Gujarat, India for providing the required laboratory and instrumental facilities and necessary infrastructure.

\section{Supporting Information}

Supporting information accompanies this paper on https://www.acgpubs.org/journal/journal-ofchemical-metrology

\section{ORCID}

Avani Chokshi: 0000-0002-6229-4804

Rohit Prajapati: 0000-0002-5636-9128

Pritesh Desai: 0000-0001-7105-598X

Mehul Patel: 0000-0002-2405-0243

\section{References}

[1] J. D. Stanaway, A. Afshin, E. Gakidou, S. S. Lim, D. Abate, K. H. Abate and F. Abd-Allah (2018). Global, regional, and national comparative risk assessment of 84 behavioural, environmental and occupational, and metabolic risks or clusters of risks for 195 countries and territories, 1990-2017: a systematic analysis for the Global Burden of Disease Study 2017, The Lancet 392, 1923-1994.

[2] G. A. Roth, D. Abate, K. H. Abate, S. M. Abay, C. Abbafati, N. Abbasi, and A. Abdelalim (2018). Global, regional, and national age-sex-specific mortality for 282 causes of death in 195 countries and territories, 1980-2017: a systematic analysis for the Global Burden of Disease Study 2017, The Lancet 392, 1736-1788.

[3] K. T. Mills, J. D. Bundy, T. N. Kelly, J. E. Reed, P. M. Kearney, K. Reynolds and J. He (2016). Global disparities of hypertension prevalence and control: a systematic analysis of population-based studies from 90 countries, Circulation 134, 441-450.

[4] K. T. Mills, A. Stefanescu and J. He (2020). The global epidemiology of hypertension, Nature Rev. Nephrolog. 16, 223237.

[5] R. M. Carey and P. K. Whelton (2018). Prevention, detection, evaluation, and management of high blood pressure in adults: synopsis of the 2017 American College of Cardiology/American Heart Association Hypertension Guideline. Annal. Internal Medicin. 168, 351-358.

[6] D. C. Goff, D. M. Lloyd-Jones, G. Bennett, S. Coady, R. B. D'agostino, R. Gibbons, C. J. O'donnell,, Robinson JG, Schwartz JS, Shero ST, Smith SC, Jr, Sorlie P, Stone NJ and Wilson P (2014). 2013 ACC/AHA guideline on the assessment of cardiovascular risk: a report of the American College of Cardiology/American Heart Association task force on practice guidelines, J. Am. Coll. Cardiol. 63(25 Pt B), 2935-2959.

[7] S. Kalra, B. Kalra and N. Agrawal, (2010). Combination therapy in hypertension: An update, Diabetol. Metab. Syndr. 2, $1-11$.

[8] D. S. Kountz, A. Goldman, J. Mikhail and M. Ezer (2012). Chlorthalidone: the forgotten diuretic, Postgrad. Med. 124, 6066.

[9] J. A. Johnson, I. Zineh, B. J. Puckett, S. P. McGorray, H. N. Yarandi and D. F. Pauly (2003). ß1-Adrenergic receptor polymorphisms and antihypertensive response to metoprolol, Clin. Pharmacol. Ther, 74, 44-52.

[10] M. Sharpe, B. Jarvis and K. L. Goa, (2001). Telmisartan. Drugs, 61, 1501-1529.

[11] V. Sawale, D. M. Dhabarde and D. K. Mahapatra (2017). Development and validation of UV spectrophotometric method for simultaneous estimation of Olmesartan Medoxomil and Chlorthalidone in bulk and tablet, Eur. J. Anal. Chem. 12, 5566.

[12] H. C. Pimple, S. S. Rane, H. D. Patil, R. Y. Chaudhari and V. R. Patil (2017). Simultaneous spectrophotometric estimation of atenolol and chlorthalidone in tablet dosage form, Int. J. Pharma. Biomed. Sci.5, 6-9

[13] N. Jain, B. K. Sharma, R. Jain, D. K. Jain and S. Jain (2012). Development and validation of UV spectrophotometric method for simultaneous estimation of cilnidipine and metoprolol succinate in bulk drugs and combined dosage form, $J$. Pharm. Biomed. Sci. 24, 102-106.

[14] A. Sheth, C. N. Patel, B. Ramlingam and N. Shah (2012). Simultaneous estimation of metoprolol succinate and chlorthalidone in pharmaceutical solid dosage form by using a developed and validated reverse phase high performance liquid chromatographic technique, Scholar. Res. J., 2, 17-21. 
[15] R. Kashyap and U. Srinivasa (2013). Development and validation of HPLC method for the simultaneous estimation of chlorthalidon and Metoprolol Succinate in bulk and dosage form, Int. J. Pharm. Drug. Anal., 1, 1-14.

[16] V. G. Dongre, S. B. Shah, P. P. Karmuse, M. Phadke and V. K. Jadhav (2008). Simultaneous determination of metoprolol succinate and amlodipine besylate in pharmaceutical dosage form by HPLC. J. Pharm. Biomed. Anal., 46, 583-586.

[17] M. D. Phale and P. D. Hamrapurkar (2009). A validated and simplified RP-HPLC of metoprolol succinate from bulk drugs, Asian J. Res. Chem. 2, 119-122.

[18] R. H. Rathod, A. S. Patil and A. A. Shirkhedkar (2018). Novel NP and RP-HPTLC in praxis for simultaneous estimation of Chlorthalidone and Cilnidipine in bulk and pharmaceutical formulation, Anal. Chem. Lett., 8, 862-871.

[19] M. Naim, A. Ahmed and K. Gj (2018). Stability indicating reverse-phase high-performance liquid chromatography method development and validation for simultaneous estimation of Telmisartan and Benidipine Hydrochloride in pharmaceutical dosage form, Asian J. Pharm. Clin. Res. 11, 342-350.

[20] N. M. Thakker, V. P. Choudhari, B. S. Kuchekar, H. B. Panchal, D. R. Rakholiya and R. Murugan (2012). Development and validation of a stability indicating RP-HPLC method for simultaneous estimation of Olmesartan Medoxomil and Metoprolol Succinate in pharmaceutical dosage form, Pharm. Methods 3, 84-89.

[21] L. R. Bhat, R. K. Godge, A. T. Vora and M. C. Damle (2007). Validated Rp-HPLC method for simultaneous determination of Telmisartan and Hydrochlorothiazide in pharmaceutical formulation. J. Liq. Chromatogr. Relat. Technol. 30, 3059-3067.

[22] P. Sravani, S. R. Kumar, N. Duganath and N. Devanna, (2014), Method development and validation for the simultaneous estimation of azilsartan and chlorthalidone by RP-HPLC in pharmaceutical dosage form, Int. J. Pharm. Pharm. Sci. 4, 725729.

[23] P. Dangre, V. Sawale, S. Meshram and M. Gunde (2015). Development and validation of RP-HPLC method for the simultaneous estimation of Eprosartan mesylate and chlorthalidone in tablet dosage form, Int. J. Pharmtech. Res. 8, 163168.

[24] S. K. Sinha, P. K. Shrivastava and S. K. Shrivastava (2012). Development and validation of a HPLC method for the simultaneous estimation of amlodipin and telmisartan in pharmaceutical dosage form, Asian Pac. J. Trop. Biomed., 2, S312S315.

[25] K. E. Parmar, R. S. Mehta, N. D. Patel and K. E. Parmar, (2013). Development and validation of HPTLC method for simultaneous determination of telmisartan and chlorthalidone in bulk and pharmaceutical dosage form. Int. j. pharm. pharm. sci. 5, 420-425.

[26] D. Desai, N. Vashi, H. Dalvadi, S. Desai and M. Hinge (2016). HPTLC method development and validation of cilnidipine and metoprolol succinate in combined dosage form, Pharm. methods 7, 28-34.

[27] P. S. Jain, M. K. Patel, S. B. Bari and S. J. Surana (2012). Development and validation of HPTLC method for simultaneous determination of amlodipine besylate and metoprolol succinate in bulk and tablets, Indian J. Pharm. Sci.74, 152-156.

[28] P. S. Nawale, A. A. Shirkhedkar, S. J. Surana and A. S. Patil (2012). Normal and reversed-phase HPTLC methods for simultaneous estimation of Telmisartan and Metoprolol Succinate in pharmaceutical formulation, Int. Scholar. Res. Notices Article ID 815353

[29] ICH [Validation of Analytical Procedures: Methodology Q2(R1)], International Conference on Harmonization, Food and Drug Administration, USA, (1996 \& 2005).

[30] https://www.fda.gov/regulatory-information/search-fda-guidance-documents/reviewer-guidance-validationchromatographic-methods (Date of last access: $11^{\text {th }}$ August 2021)

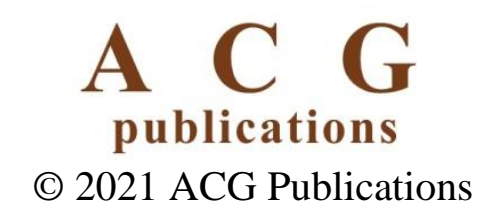

